\title{
Histopathologic analysis of stage pT1b kidney neoplasms for optimal surgical margins of nephron-sparing surgery
}

\author{
G. $\mathrm{Li}^{1} \cdot \mathrm{Q} . \mathrm{LuO}^{1} \cdot$ Z. $\mathrm{Lang}^{2} \cdot \mathrm{Y}^{\mathrm{Li}} \mathrm{Li}^{3} \cdot \mathrm{A} . \mathrm{Wang}^{4} \cdot \mathrm{K} . \mathrm{Wang}^{5} \cdot \mathrm{Y}^{\mathrm{Niu}}{ }^{1}$ (i)
}

Received: 8 January 2018 / Accepted: 13 February 2018 / Published online: 21 March 2018

(c) The Author(s) 2018

\begin{abstract}
Objective To evaluate the pathological features and define the optimal surgical margins (SM) of nephron-sparing surgery (NSS) for kidney neoplasms 4-7 cm (stage pT1b) on preoperative imaging.

Materials and methods The retrospective study included 748 patients who were diagnosed stage pT1b renal tumors and underwent either radical nephrectomy (RN, $n=475)$ or NSS ( $n=273)$ from January 2004 to March 2017. The tumor size, pathological subtype, Fuhrman grade, status of peritumoral pseudocapsule (PC) and tumor multifocality were recorded. The relationship between peritumoral PC and positive SM was calculated statistically by Fisher's exact probability test.

Results The mean tumor diameter was $5.4 \mathrm{~cm}$ (range: $4.1-7.0 \mathrm{~cm}$ ), $65(8.7 \%)$ cases were discovered with multifocal lesions and $686(91.7 \%)$ were surrounded with peritumoral PC in all 748 specimens. $57(8.3 \%)$ of 686 cases were proved with tumor infiltrated beyond PC [infiltration (+)], and the presence of PC infiltration (+) was significantly correlated with positive SM $(p=0.016)$. The infiltrative depth of tumor cells into renal parenchyma beyond PC was all limited in $3 \mathrm{~mm}$ and the proportion of $\leq 1,1-2$ and $2-3 \mathrm{~mm}$ was $21.1 \%$ (12/57), 59.6\% (34/57) and 19.3\% (11/57), respectively.

Conclusions Our report indicates a $3 \mathrm{~mm}$ excisional margin is acceptable to ensure negative SM when operating NSS on stage pT1b kidney neoplasms.
\end{abstract}

Keywords Kidney neoplasms $\cdot$ Nephron-sparing surgery $\cdot$ Positive surgical margins $\cdot$ Peritumoral pseudocapsule $\cdot$ Multifocality

\section{Abbreviations \\ NSS Nephron-sparing surgery \\ RN Radical nephrectomy \\ PC Pseudocapsule}

Gang Li, Qiang Luo and Zhiqiang Lang are co-first authors.

\section{Y. Niu}

yuanjieniutmu@sina.com

1 Department of Urology, Tianjin Institute of Urology, The Second Hospital of Tianjin Medical University, No. 23, Pingjiang Rd, Tianjin 300211, China

2 Department of Pathology, Yuhuangding Hospital of Qingdao University, Yantai, Shandong, China

3 Department of Pathology, The People's Hospital of Liaocheng, Liaocheng, Shandong, China

4 Department of Uropathology, Tianjin Institute of Urology, The Second Hospital of Tianjin Medical University, Tianjin, China

5 Department of Urology, Yuhuangding Hospital of Qingdao University, Yantai, Shandong, China
SM Surgical margins

CT Computed tomography

MRI Magnetic resonance imaging

\section{Introduction}

Kidney neoplasms accounts for almost 3\% of all malignant tumors [1], which includes variable kinds of pathological subtypes and different histopathological features. Nephronsparing surgery (NSS) has been an optional manner for stage pT1a-1b (tumor diameter $\leq 7 \mathrm{~cm}$ ) kidney tumors. Nevertheless, it is still controversial to confirm the optimal surgical margins (SM) for pT1b tumors [2, 3]. In the present study, we collected data from 748 cases of stage $\mathrm{pT} 1 \mathrm{~b}$ renal tumors and analyzed their pathological features retrospectively, especially the relationship between positive SM after NSS with the infiltrative situation of peritumoral pseudocapsule (PC). The main purpose of this study is to provide our experience and define the optimal SM when operating NSS for pT1b stage renal carcinomas. 


\section{Materials and methods}

\section{Patients}

This retrospective study was approved by the ethical committee of the Second Hospital of Tianjin Medical University. 748 patients who were diagnosed stage pT1b renal carcinoma and underwent either RN $(n=475)$ or NSS $(n=273)$ from January 2004 to March 2017 in three institutional centers were enrolled in this study. All lesions in this research were unilateral, pathologically proved and without local or distant metastasis, hereditary tumors were excluded as well. Incorporated patients accepted preoperative ultrasonography of urinary system, abdominal computed tomography (CT) or magnetic resonance imaging (MRI) and chest X-ray to clarify tumor location, tumor size, TNM classification and the presence of metastatic lesions. A total of 527 (70.5\%) males and 221 (29.5\%) females were enrolled, with a male/female ratio of 2.38:1.00. The average age of patients was 60.2 (range: 26-88) years. 369 (49.3\%) tumors were located in left kidneys and other 379 (50.7\%) were in right (Table 1). Major clinical symptoms of $124(16.6 \%)$ patients were gross hematuria, $85(11.4 \%)$ were renal area pain, 49 (6.5\%) were both gross hematuria and pain, other $490(65.5 \%)$ cases had no obvious symptoms.

\section{Clinicopathological assessment}

The excisional margin of NSS was along the visible renal parenchyma, about 5-10 $\mathrm{mm}$ from tumor surface. For specimens of RN, we resected a 5-10 mm thickness of renal parenchyma around cancerous lesions in vitro and then performed pathological examination. The tumor size, pathological subtype, Fuhrman grade, peritumoral PC status and tumor multifocality were recorded and assessed. The highest representation of tumor-kidney interface of specimens was selected to standardize the material. Pathological data were done according to the 2004 WHO histopathological classification and 2010 AJCC TNM staging system. Peritumoral PC was defined as the presence of continuous fibrous tissue at the interface of tumor and adjacent renal parenchyma. PC status could be divided into 2 groups: Infiltration (-) means peritumoral PC was complete and no tumor cells infiltrated beyond it (Fig. 1a, b); Infiltration (+) means neoplastic cells infiltrated beyond peritumoral PC, even reached peritumoral normal renal parenchyma (Fig. 1c, d). The infiltrative depth of cancer cells in normal renal parenchyma beyond PC was also measured microscopically for each specimen. Tumor multifocality was defined as two or more lesions occurred in
Table 1 Clinical and pathological characteristics of all patients

\begin{tabular}{ll}
\hline Characteristics & Value \\
\hline No. of patients & 748 \\
Age (years) & \\
Range & $26-88$ \\
Average & 60.2 \\
Sex & \\
Male & $527(70.5 \%)$ \\
Female & $221(29.5 \%)$ \\
Tumor location & \\
Left & $369(49.3 \%)$ \\
Right & $379(50.7 \%)$ \\
Tumor diameter (cm) & \\
Range & $4.0-7.0$ \\
Average & 5.4 \\
Pathological subtype & \\
Clear cell & $563(75.3 \%)$ \\
Chromofobe & $48(6.4 \%)$ \\
Papillary & $43(5.7 \%)$ \\
Others & $94(12.6 \%)$ \\
Fuhrman grade & \\
1 & $152(20.3 \%)$ \\
2 & $528(70.6 \%)$ \\
3 & $47(6.3 \%)$ \\
4 & $21(2.8 \%)$ \\
Peritumoral pseudocapsule & $62(8.3 \%)$ \\
Absent & $686(91.7 \%)$ \\
Present & $65(8.7 \%)$ \\
\hline
\end{tabular}

homolateral kidney with intervening normal renal parenchyma (Fig. 2a). Positive SM was certified by postoperative pathological examination (Fig. 2b).

\section{Statistical analysis}

The Fisher's exact probability test was used to compare the relationship between peritumoral PC and positive SM. A $p<0.05$ was considered as statistical difference. Statistical analyses were performed using the Statistical Package for Social Sciences software version 20.0 (SPSS, Chicago, IL).

\section{Results}

The clinical and pathological characteristics of patients are shown in Table 1. The mean tumor diameter was 5.4 (range: $4.1-7.0) \mathrm{cm}$. Based on the 2004 WHO classification, 563 (75.3\%) cases were clear cell renal cell carcinoma (RCC), 
Fig. 1 Representative figures of peritumoral PC $(\mathrm{H} \& \mathrm{E} \times 100)$. a, b Peritumoral PC was intact and no tumor cells infiltrated beyond it; $\mathbf{c}, \mathbf{d}$ tumor cells infiltrated beyond peritumoral PC. $P C$ pseudocapsule, $T$ tumor, $K$ kidney

Fig. 2 Representative figures of multifocal tumors and positive SM. a multifocal tumors by microscopic examination $(\mathrm{H} \& \mathrm{E} ; \times 100)$; b positive SM by pathological examination (ink dyed and $\mathrm{H} \& \mathrm{E} \times 400$ ). SiM surgical margins, $P C$ pseudocapsule, $T$ tumor, $K$ kidney
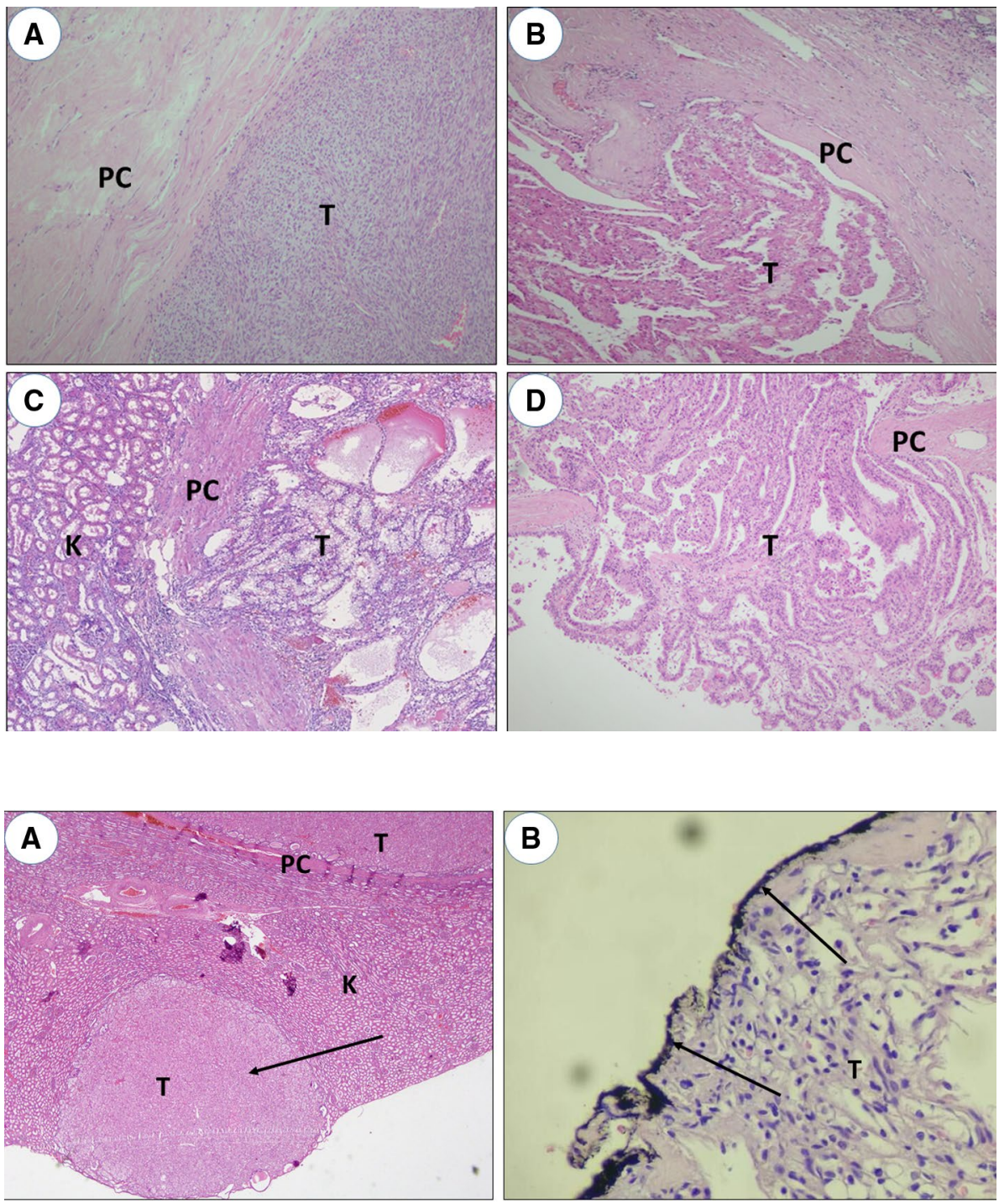

48 (6.4\%) were chromofobe RCC, 43 (5.7\%) were papillary RCC and the remainders (12.6\%) were other subtypes. Fuhrman grade I-IV was found in $152(20.3 \%), 528(70.6 \%)$, 47 (6.3\%) and 21 (2.8\%) patients, respectively. Among 748 specimens, $686(91.7 \%)$ cases were surrounded with peritumoral PC and 65 (8.7\%) cases were discovered with multifocal masses. 20 (30.8\%) multifocal lesions were discovered via preoperative imaging and other $45(69.2 \%)$ through postoperative pathological test.

57 (8.3\%) of 686 specimens were proved with PC infiltration $(+)$, and the infiltrative depth of tumor cells into peritumoral renal parenchyma beyond PC was all limited in $3 \mathrm{~mm}$ from primary tumor surface. The infiltrative distance in renal parenchyma of $\leq 1,1-2$ and $2-3 \mathrm{~mm}$ was $12(21.1 \%), 34$ (59.6\%) and $11(19.3 \%)$ cases, respectively (Table 2).

Peritumoral PC was detected in $254(93.0 \%)$ of 273 patients who underwent NSS. In these 254 specimens,
Table 2 The infiltrative depth of tumor cells in peritumoral normal renal parenchyma beyond PC

\begin{tabular}{ll}
\hline Infiltrative depth & Value \\
\hline No. of patients & 57 \\
$\leq 1 \mathrm{~mm}$ & $12(21.1 \%)$ \\
$1-2 \mathrm{~mm}$ & $34(59.6 \%)$ \\
$2-3 \mathrm{~mm}$ & $11(19.3 \%)$ \\
$>3 \mathrm{~mm}$ & $0(0)$ \\
\hline
\end{tabular}

$P C$ pseudocapsule

the situation of PC infiltration (+) and (-) were found in $19(7.5 \%)$ and $235(92.5 \%)$ cases separately. Positive SM was discovered in 8 (2.9\%) of 273 patients pathologically and all of the 8 kidney neoplasms were surrounded with PC. Statistical analysis shows the presence of PC infiltration $(+)$ was significantly correlated with positive SM $(p=0.016)$, as shown in Table 3 . 
Table 3 The relationship of PC infiltration and positive SM

\begin{tabular}{|c|c|c|c|}
\hline \multirow[t]{2}{*}{ Infiltration } & \multicolumn{2}{|l|}{ SM } & \multirow[t]{2}{*}{$p$ value } \\
\hline & $(+)$ & $(-)$ & \\
\hline$(+)$ & 3 & 16 & \\
\hline$(-)$ & 5 & 230 & 0.016 \\
\hline
\end{tabular}

\section{Discussion}

Kidney neoplasms occupy approximately $3 \%$ of reported human tumors worldwide, and the morbidity in developed countries is higher than developing countries [1, 4]. Surgical resection is the dominant treatment for localized renal neoplasms. With the improvement of surgical techniques and an increasing awareness of the long-term postoperative renal function, NSS has been widely accepted by urologists and applied in renal carcinomas $4 \mathrm{~cm}$ or less in recent years. Compared with RN, NSS is preferable to preserve more renal parenchyma and obtain better oncologic outcomes through long-term follow-up [5, 6]. Leibovich et al. [7] retrospectively compared outcomes of 91 stage pT1b patients treated with NSS and 841 pT1b patients with RN, and concluded that no significant differences of cancer-specific survival or distant metastases-free survival between two groups. Such similar conclusions were proved in other literatures as well [8-10].

Compared with RN, NSS takes advantage of renal functional preservation, oncological control and maximizing prevention of tumor recurrence. Whether positive SM is significantly correlated with long-term risk of local recurrence and distant organic metastasis still remains controversial [11-14]. A number of researches have been conducted to define an optimal excisional margin. Zucchi et al. [15] proposed a $10 \mathrm{~mm}$ margin of normal-appearing parenchyma in operating NSS was enough for pT1b kidney cancer to ensure negative SM and decrease the risk of tumor recurrence. While, some authors considered such resection distance might lead to an unnecessary overexcision of normal parenchyma and increase the incidence of surgical complications, such as postoperative bleeding, damage of urinary collecting system and hilar vessels. Sutherland [16] stated a margin width of normal renal parenchyma less than $5 \mathrm{~mm}$ during PN for stages T1-2N0M0 RCC was suitable and safe to ensure a negative SM. Nevertheless, Akcetin et al. [17] suggested a $2 \mathrm{~mm}$ surgical distance for tumors $<5 \mathrm{~cm}$ was safe enough on survival after NSS, and an additional resection was unnecessary and irrelevant with postoperative progression. Berdjis et al. [18] explored 121 patients with NSS and concluded that the width of resection margin did not have influence on the risk of tumor recurrence. Chen et al. [19] retrospectively analyzed 87 specimens of T1b RCC and found 34 (39\%) cases had extra-PC cancerous lesions. The distance of such lesions distributed in 1, 2, $3 \mathrm{~mm}$ was 11 , 21 and $7 \%$, respectively, and they recommended a $4 \mathrm{~mm}$ optimal SM. In our report, we found the presence of tumor cells infiltrated beyond peritumoral PC was significantly correlated with positive SM $(p=0.016)$ and all extra-PC lesions were within the width of $3 \mathrm{~mm}$ from primary tumor surface as well. Accordingly, a resection margin of $2 \mathrm{~mm}$ or less is not appropriate, especially for tumors which infiltrate into renal parenchyma beyond PC. To ensure a negative SM, we recommend an excisional distance of $3 \mathrm{~mm}$ at least is reliable.

The dominant concerns against NSS derive from the presence of multifocal neoplasms, which was recognized by either preoperative imaging or postoperative pathological examination. In a review paper published earlier this year, the authors indicated that removing all discernible tumors was likely more important than excess SM width [20]. Lee et al. [21] found that tumor multifocality existed in $5.3 \%$ (57/1071) RN specimens and only 33.3\% (19/57) could be discovered on preoperative imaging, undetected occult multifocality was present in 3.5\% (38/1071) RCC patients. Nevertheless, Whang et al. [22] reported an obvious higher proportion, of which $25 \%$ (11/44) of RCC demonstrated pathological multifocality and multifocal rate was independent of the size of primary tumors. In a meta-analysis of 1180 patients who underwent NSS, authors discovered the incidence of multifocal renal lesions was approximately $15 \%$ and it depended on tumor size, histology and stage [23]. The discrepancy of reported multifocal incidences was potentially caused by the difference of pathological methodology. In our study, the frequency of tumor multifocality was $8.7 \%$ (65/748), which was in accordance with reported ratio. Small multifocal lesions were easily visualized through preoperative imaging examination (only $13.1-44 \%$ cases were recognized [24-26]), including abdominal ultrasound, CT or MRI. In the present study, preoperative imaging detected $20(30.8 \%)$ multifocal lesions only, other 45 (69.2\%) were discovered via pathological test. The missing satellites might lead to tumor recurrence or positive SM [27], while it is still unclear whether multifocal foci is capable of progressing to local or distant metastatic tumors. A retrospective research revealed that compared with unifocal tumor, no statistic difference of overall survival, disease-free survival and diseasefree rate was found in multifocal group after a 3 and 5 years' follow-up [21].

Here, we provided our experience and advice to avoid postoperative positive SM and tumor recurrence for NSS on stage pT1b kidney tumors. First, the safe distance of SM away from tumor which is infiltrated into renal parenchyma should better be more than $3 \mathrm{~mm}$. For tumors surrounded with intact peritumoral PC, an intraoperative frozen-section examination is not necessary and propositional (EAU 
guidelines). Moreover, it is important to inspect carefully whether multifocal neoplasms exist around the primary tumor according to preoperative imaging examination and intraoperative visual field. If so, all multifocal lesions should be excised entirely during surgery to prevent residual cancer cells.

There were also some limitations, including that our research was a retrospective analysis and non-randomized design which could potentially decrease the level of evidence. Besides, the pathological data were collected from different medical institutions over a long period and the procedures of handling specimens were not uniform. Despite these limitations, we had faith in the usefulness of our results for surgeons to perform optimal SM during operation. These findings need to be validated in future prospective studies.

\section{Conclusion}

Our analysis about stage pT1b kidney neoplasms showed that positive SM was statistically related to the status of peritumoral PC and the infiltrative depth of tumor cells in normal renal parenchyma beyond PC was all limited in $3 \mathrm{~mm}$. Thus, a $3 \mathrm{~mm}$ resection margin of renal parenchyma is appropriate to ensure negative SM. When operating NSS on stage pT1b patients, we recommend careful pre- and intra-operative inspection for multifocal tumors to prevent residual cancer cells and tumor recurrence.

Funding This work was supported by National Natural Science Foundation of China (grants 81472682 and 81772756), and Natural Science Foundation of Tianjin (17JCZDJC35300, 15JCZDJC35400 and 15JCYBJC27200), and Tianjin Municipal Natural Science Foundation (grant 17JCYBJC26000).

\section{Compliance with ethical standards}

Conflict of interest The authors declare that they have no conflict of interest.

Ethical approval This study has been approved by The Second Hospital of Tianjin Medical University's ethics committee and has been performed according to the ethical standards laid down in the 1964 Declaration of Helsinki.

Informed consent Informed consent was obtained from all individual participants included in the study.

Open Access This article is distributed under the terms of the Creative Commons Attribution 4.0 International License (http://creativeco mmons.org/licenses/by/4.0/), which permits unrestricted use, distribution, and reproduction in any medium, provided you give appropriate credit to the original author(s) and the source, provide a link to the Creative Commons license, and indicate if changes were made.

\section{References}

1. Ferlay J, Shin HR, Bray F, Forman D, Mathers C, Parkin DM. Estimates of worldwide burden of cancer in 2008: GLOBOCAN 2008. Int J Cancer. 2010;127(12):2893-917.

2. Simmons MN, Weight CJ, Gill IS. Laparoscopic radical versus partial nephrectomy for tumors $>4 \mathrm{~cm}$ : intermediate-term oncologic and functional outcomes. Urology. 2009;73(5):1077-82.

3. Cooperberg MR, Mallin K, Kane CJ, Carroll PR. Treatment trends for stage I renal cell carcinoma. J Urol. 2011;186(2):394-9.

4. Lindblad P. Epidemiology of renal cell carcinoma. Scand J Surg. 2004;93(2):88-96.

5. Fergany AF, Hafez KS, Novick AC. Long-term results of nephron sparing surgery for localized renal cell carcinoma: 10-year followup. J Urol. 2000;163(2):442-5.

6. Huang WC, Elkin EB, Levey AS, Jang TL, Russo P. Partial nephrectomy versus radical nephrectomy in patients with small renal tumors-is there a difference in mortality and cardiovascular outcomes? J Urol. 2009;181(1):55-61 (discussion 61-52).

7. Leibovich BC, Blute M, Cheville JC, Lohse CM, Weaver AL, Zincke H. Nephron sparing surgery for appropriately selected renal cell carcinoma between 4 and $7 \mathrm{~cm}$ results in outcome similar to radical nephrectomy. J Urol. 2004;171(3):1066-70.

8. Joniau S, Vander Eeckt K, Srirangam SJ, Van Poppel H. Outcome of nephron-sparing surgery for $\mathrm{T} 1 \mathrm{~b}$ renal cell carcinoma. BJU Int. 2009;103(10):1344-8.

9. Lee HJ, Liss MA, Derweesh IH. Outcomes of partial nephrectomy for clinical T1b and T2 renal tumors. Curr Opin Urol. 2014;24(5):448-52.

10. Capitanio U, Terrone C, Antonelli A, Minervini A, Volpe A, Furlan M, Matloob R, Regis F, Fiori C, Porpiglia F, Di Trapani E, Zacchero M, Serni S, Salonia A, Carini M, Simeone C, Montorsi F, Bertini R. Nephron-sparing techniques independently decrease the risk of cardiovascular events relative to radical nephrectomy in patients with a T1a-T1b renal mass and normal preoperative renal function. Eur Urol. 2015;67(4):683-9.

11. Yossepowitch O, Thompson RH, Leibovich BC, Eggener SE, Pettus JA, Kwon ED, Herr HW, Blute ML, Russo P. Positive surgical margins at partial nephrectomy: predictors and oncological outcomes. J Urol. 2008;179(6):2158-63.

12. Kang HW, Lee SK, Kim WT, Yun SJ, Lee SC, Kim WJ, Hwang EC, Kang SH, Hong SH, Chung J, Kwon TG, Kim HH, Kwak C, Byun SS, Kim YJ. Surgical margin does not influence recurrence rate in pT1 clear cell renal cell carcinoma after partial nephrectomy: a multicenter study. J Surg Oncol. 2016;114(1):70-4.

13. Shah PH, Moreira DM, Okhunov Z, Patel VR, Chopra S, Razmaria AA, Alom M, George AK, Yaskiv O, Schwartz MJ, Desai M, Vira MA, Richstone L, Landman J, Shalhav AL, Gill I, Kavoussi LR. Positive surgical margins increase risk of recurrence after partial nephrectomy for high risk renal tumors. J Urol. 2016;196(2):327-34.

14. Kryvenko ON. Positive surgical margins increase risk of recurrence after partial nephrectomy for high risk renal tumors. Shah PH, Moreira DM, Okhunov Z, Patel VR, Chopra S, Razmaria AA, Alom M, George AK, Yaskiv O, Schwartz MJ, Desai M, Vira MA, Richstone L, Landman J, Shalhav AL, Gill I, Kavoussi LR. J Urol. 2016 Aug;196(2):327-34. Urol Oncol. 2017;35(6):449-50.

15. Zucchi A, Mearini L, Mearini E, Costantini E, Vivacqua C, Porena M. Renal cell carcinoma: histological findings on surgical margins after nephron sparing surgery. J Urol. 2003;169(3):905-8.

16. Sutherland SE, Resnick MI, Maclennan GT, Goldman HB. Does the size of the surgical margin in partial nephrectomy for renal cell cancer really matter? J Urol. 2002;167(1):61-4. 
17. Akcetin Z, Zugor V, Elsasser D, Krause FS, Lausen B, Schrott KM, Engehausen DG. Does the distance to normal renal parenchyma (DTNRP) in nephron-sparing surgery for renal cell carcinoma have an effect on survival? Anticancer Res. 2005;25(3a):1629-32.

18. Berdjis N, Hakenberg OW, Zastrow S, Oehlschlager S, Novotny V, Wirth MP. Impact of resection margin status after nephron-sparing surgery for renal cell carcinoma. BJU Int. 2006;97(6):1208-10.

19. Chen XS, Zhang ZT, Du J, Bi XC, Sun G, Yao X. Optimal surgical margin in nephron-sparing surgery for $\mathrm{T} 1 \mathrm{~b}$ renal cell carcinoma. Urology. 2012;79(4):836-9.

20. Laganosky DD, Filson CP, Master VA. Surgical margins in nephron-sparing surgery for renal cell carcinoma. Current Urol Rep. 2017;18(1):8.

21. Richstone L, Scherr DS, Reuter VR, Snyder ME, Rabbani F, Kat$\tan$ MW, Russo P. Multifocal renal cortical tumors: frequency, associated clinicopathological features and impact on survival. J Urol. 2004;171(2 Pt 1):615-20.

22. Whang M, O'Toole K, Bixon R, Brunetti J, Ikeguchi E, Olsson CA, Sawczuk TS, Benson MC. The incidence of multifocal renal cell carcinoma in patients who are candidates for partial nephrectomy. J Urol. 1995;154(3):968-70 (discussion 970-961).

23. Uzzo RG, Novick AC. Nephron sparing surgery for renal tumors: indications, techniques and outcomes. J Urol. 2001;166(1):6-18.

24. Kletscher BA, Qian J, Bostwick DG, Andrews PE, Zincke H. Prospective analysis of multifocality in renal cell carcinoma: influence of histological pattern, grade, number, size, volume and deoxyribonucleic acid ploidy. J Urol. 1995;153(3 Pt 2):904-6.

25. Baltaci S, Orhan D, Soyupek S, Beduk Y, Tulunay O, Gogus O. Influence of tumor stage, size, grade, vascular involvement, histological cell type and histological pattern on multifocality of renal cell carcinoma. J Urol. 2000;164(1):36-9.

26. Sargin SY, Ekmekcioglu O, Arpali E, Altinel M, Voyvoda B. Multifocality incidence and accompanying clinicopathological factors in renal cell carcinoma. Urol Int. 2009;82(3):324-9.

27. Zhang K, Xie WL. Determination of the safe surgical margin for T1b renal cell carcinoma. Urol J. 2017;14(1):2961-7. 